\title{
Dilemmas of Difference: Teaching the 'Non-West' Critically
}

\author{
Mary Curran and Susan M. Roberts \\ University of Kentucky
}

In this paper we reflect upon our experiences teaching a required undergraduate course on the so-called 'non-western world' at the University of Kentucky, USA. We describe the course and summarise the development of the rationale for a 'cross-cultural' component as a requirement for all students. In particular, we discuss the challenges entailed in teaching about difference in a way that engenders a critical approach to global inequalities and relations. We raise the question of how to assess our effectiveness as critical geographers in the classroom, and conclude by suggesting the need for a more open and serious debate over teaching critically.

\section{Introduction}

Recently several self-described critical geographers have issued calls for a more explicit and sustained consideration of the classroom as a site of engagement and activism (e.g. Castree, 2000; Heyman, 2000). Yet, thus far, the debate on teaching by critical geographers has barely begun and remains quite general. We therefore welcome this opportunity to consider some aspects of teaching geography critically. In this essay, we connect general concerns over critical engagement in the classroom to some specific and pragmatic concerns we face as instructors.

We teach at the University of Kentucky, a public land-grant research university in the US South. Each of us regularly teaches GEO160 'Lands and Peoples of the Non-Western World' - a course that alternately delights and frustrates us. It presents both thorny pedagogic and political dilemmas, while at the same time it gives us opportunities to challenge and destabilise students' taken-for-granted sense of the world and their places in it. It is upon our experiences teaching this particular introductory undergraduate course that we reflect in this essay.

\section{Teaching the 'Non-West'}

The University of Kentucky (UK), like most - if not all - research universities in the USA, has general education requirements. Such requirements typically include some foreign language instruction, courses in basic calculus or inferential statistics, and in communication skills, for example. At UK these are called the 'University Studies Program' and represent the institutionalisation of the classic US ideals of a 'liberal' education, expressed in the University's official Bulletin in this way:

A university education truly worth the name must do more than prepare students for a job or a career. It must broaden their understanding of the world, of themselves, of their role in society, and of the ideals and 
aspirations which have motivated human thought and action throughout the ages. [...]

The broad goals of the University of Kentucky's general education program, called University Studies, make for mature, open, flexible individuals who can adapt to changing situations, learn new skills, and meet unforeseen challenges in their careers. At the same time, University Studies will help students to develop their own sense of values, to pursue their own goals, and to contribute to the political, moral, social, and cultural enrichment of society. (UK, 2000)

Each undergraduate, whatever his or her major, must satisfy the five components of the University Studies Program before graduation. One of the components is the 'Cross-Cultural Requirement'. This is officially described in the University's Bulletin:

The principal objective of the Cross-Cultural portion of University Studies is to enable students to identify and describe some of the major dimensions of a non-Western or Third World culture. (UK, 2000)

The cross-cultural requirement was added to the University Studies Program in the mid-1980s. This new requirement was a (belated) response to critiques of eurocentrism in US liberal education, but the push to mandate students' exposure to cultures 'different' from their own should also be seen within the wider context of the rise of 'Area Studies' in US universities (see Rafael, 1999; Wallerstein, 1996). Institutionally, the non-west was seen as the disciplinary territory of Anthropology and Geography and, indeed, these departments seized the new requirement as a strategic opportunity to at once increase student enrolment and bolster the departments' arguments for additional personnel. Only Anthropology and Geography regularly offer 100-level (introductory) courses that satisfy this requirement. In each academic year, ANT160 (Cultural Diversity in the Modern World) is taken by about 700 students and GEO160 is taken by over 1400 . GEO160 is offered in several classes each semester and each class has about 75 students in it. Although it is officially an introductory or freshman course, in a typical GEO160 class there are many senior students who have put off fulfilling the requirement. In addition, students taking the course come from all majors on campus, from accounting to pharmacy. Most students in GEO160, when asked why they are taking the course will say 'to fulfil the cross-cultural requirement'; rarely do students enrol out of any deep-felt interest in the course material and several express their resentment at having to take such a course at all.

The University of Kentucky has not been immune to wider intellectual currents. GEO160 has found itself living the tensions between a liberal multiculturalism - celebrating diversity - on the one hand, and, on the other, a more critical approach based upon interrogation of the ways in which cultural diversity is represented and embedded within hierarchies of difference. As recently as 1995-96, GEO160 was described as the 'study of selected cultures of India, China, Southeast Asia, the Middle East, Africa, and South America,' with emphases on 'languages, religions, food, and physical environment, with an emphasis on how specific non-Western cultural landscapes arise from the interactions of land, 
people, and culture' (UK, 1995). The official course description was rewritten to reflect more accurately the more explicitly critical approach taken by most faculty members and teaching assistants who taught the course. It now reads:

The geographic study of the conceptual and historical definition of regions of the world as 'Non-Western'. Global patterns of social, cultural, economic, and political difference between the West and Non-West as well as the processes key to the making of the Non-Western world (such as colonialism and imperialism) are discussed. In addition, selected current issues of significance to peoples in the Non-Western world, such as sustainable development, environment, human rights, and gender relations, are considered. (UK, 2000)

This description speaks to the way instructors place cultural diversity within its political economic and historical contexts.

Of course, one key difficulty faced by instructors of this course is its very title itself. From the beginning, 'difference' in the language of the cross-cultural requirement, was articulated in terms of west/non-west (with the non-west standing in close relation to a sometimes-specified 'Third World'). Yet, what is the non-western world? How does such a binary (west/non-west) and division of global social space into two apparently unproblematic zones make sense? (Hopper, 2001). Risking, as it does, encoding a 'new orientalism', this framing is not something within which one can teach without deconstruction; deconstruction through which we can challenge such definition and demarcation of global space and populations (Spivak, 1993:57; cf. Spivak, 1995). One of us uses a simple exercise at the beginning of the course. The students are asked what qualities they, or they think that people in general, associate with the terms 'west' and 'non-west.' In so doing, it immediately becomes clear that: the west stands as the norm; the non-west is conflated with a host of other demarcations of global space (such as 'Third World', developing world, etc.); and that it is very difficult and quite undesirable to try to characterise and define spaces and populations in this way. Our students typically initially associate the non-west with terms such as poor, undeveloped, technologically inferior, traditional and chaotic. The other one of us asks students to write down the adjectives that come into their minds when they hear the phrase the non-western world. The compilation of their adjectives becomes an important component of the subsequent discussions of the west and non-west as historical notions embedded within global power relations (Hall, 1992). At the end of the semester, students' lists of adjectives are returned and each is asked to write an essay that explains how he or she now thinks about the adjectives and the non-western world as a category. Our courses are thus designed to prompt students to critically evaluate the adjectives they first associated with the non-west and to understand the very real historical and on-going effects of such representations of 'other' spaces and people.

We have found that these sorts of exercises can effectively challenge our students' identities as predominantly 'young, white, relatively unmarked subjects' (McDowell, 1994: 245). By this we mean that they occupy a privileged position against which all other locations are judged and found lacking. Our challenge is to examine the nature of this privilege, interrogate the ways in which it is maintained, and thereby mark their positions within a global system of 
power relations. Although students commonly expect the course to be more along the lines of a cultural tour of 'exotic' others, we encourage them to see themselves in relation to others, in relationships that are constructed through power. We present 'connections from person to person and place to place' as a political project (Smith, 2000: 338) to challenge students' narrow sense of the political and make them see their roles within a global political economy. For example, through discussions of the linkages between cartography and colonialism, students' uncritical acceptance of maps as directly corresponding to a 'reality' is challenged and the political nature of maps and mapping is brought to the surface. Although some students are uncomfortable with this, others are stimulated by this extension of the political into that which they had taken to be matter of fact and somehow non-political. Similarly, when the politics of tourism are brought into the classroom, some students react with disappointment or anger because their guilt-free vacations in the tropics are threatened by the knowledge, while, again, others find the politics compelling.

We recognise that, in opening students' eyes to unequal political relations, we run the risk of reinforcing quiescence - because students often are so overwhelmed that they see little possibility for intervention. To prevent student despair, we introduce activist groups and political movements in a number of forms, from student movements in South Korea, Southern church groups, the Zapatistas, the American Indian Movement and the panoply of affinity groups involved in WTO protests in Seattle and elsewhere. This permits us to bring the voices of the 'other' into the classroom, a strategy that demands careful and analytic contexualisation to enable students to see the always partial and political nature of knowledge and knowledge production (McDowell, 1994).

In many ways, our own voices as critical geographers can seem very strange to our students' ears. Because GEO160 may be their first exposure to any sort of critical social thought, our analyses can seem unrelated to their everyday lives, in spite of our best efforts to make plain the ways in which our lives in Kentucky are linked to those in the space labelled non-west. Even students who grasp such connections and relations - in other words those who seem to 'get it' - often do not imagine ways to effect social change. We wonder: Why aren't they storming the barricades? Why aren't there noticeable ripple effects outside of the classroom? What 'learning outcomes' are satisfactory for critical geographers teaching this material? Is it enough that a few may develop a heightened interest in world affairs or social justice or a more sceptical attitude toward mainstream media and governmental actions? How satisfied, as critical geographers, can we be with these outcomes? We know how to measure our students' comprehension, but how do we know when we have succeeded or failed as critical geographers in the classroom?

\section{Conclusions}

Each of us has devoted considerable time, intellectual (and emotional) energy to designing and teaching this course over the years. Moreover, in everyday hallway conversations we find ourselves sharing our teaching experiences and ideas with each other and with colleagues and friends. We suspect that these conversations go on in most departments. Any insights about the failures and 
successes of teaching critically seem to have remained largely unsystematised and unwritten (cf. hooks, 1989). This situation mirrors and reinscribes institutional/corporate imperatives based on the relative valorisation of research (or, more particularly, research productivity counted in publications and grants) over teaching. As several critical geographers have noted, a systematic and practical conversation in print about the possibilities our classrooms hold is overdue.

\section{References}

Castree, N. (2000) Professionalisation, activism, and the university: Whither 'critical geography'? Environment and Planning A 32 (6), 955-70.

Hall, S. (1992) The West and the rest: Discourse and power. In S. Hall and B. Giebens (eds) Formations of Modernity (pp. 276-95). Oxford: Polity, in association with Open University.

Heyman, R. (2000) Research, pedagogy, and instrumental geography. Antipode 32 (3), 292-307.

hooks, b. (1989) Talking Back: Thinking Feminist, Thinking Black. Boston, MA: South End Press.

Hopper, H.L. (2001) Personal communication. January.

McDowell, L. (1994) Polyphony and pedagogic authority. Area 26 (3), 241-8.

Rafael, V.L. (1999) The cultures of area studies in the United States. Social Text 41,91-112.

Smith, N. (2000) Afterword: Who rules this sausage factory? Antipode 32 (3), 330-9.

Spivak, G.C. (1993) Outside in the Teaching Machine. New York: Routledge.

Spivak, G.C. (1995) Teaching for the times. In J. Nederveen Pieterse and B. Parekh (eds) The Decolonization of Imagination: Culture, Knowledge and Power (pp. 176-202). London: Zed Books.

University of Kentucky (1995) Undergraduate bulletin, 1995-1996. Lexington, KY: University of Kentucky.

University of Kentucky (2000) Undergraduate bulletin, 2000-2001. Lexington, KY: University of Kentucky.

Wallerstein, I. (1996) Open the social sciences. Items 50 (1), 1-6. Social Science Research Council. 